\title{
Marine connectivity: a new look at pelagic larval duration and genetic metrics of dispersal
}

\author{
K. A. Selkoe ${ }^{1,2, *}$, Robert J. Toonen ${ }^{1}$ \\ ${ }^{1}$ Hawai'i Institute of Marine Biology, University of Hawai'i, Kāne`ohe, Hawai'i 97644, USA \\ ${ }^{2}$ National Center for Ecological Analysis and Synthesis, 735 State St., Santa Barbara, California 93101, USA
}

\begin{abstract}
Understanding connectivity remains a fundamental challenge to marine ecology due to technical limitations of tracking larval dispersal. Marine population genetic analyses are often used to make inferences about the scale of population connectivity. For species with a larval phase, pelagic larval duration (PLD) is assumed to influence the scale of connectivity. If PLD and genetic metrics are reliable proxies of connectivity, the 2 should be well correlated. Previous tests report conflicting results, with many reports that global $F_{\mathrm{ST}}$ (Wright's fixation index) correlates poorly with PLD, and one very high correlation of isolation-by-distance (IBD) slope, which is derived from $F_{\mathrm{ST}}$, with PLD. First we clarify the expectations for the performance of these different proxies in light of the latest understanding of larval dispersal dynamics. We then test the hypothesis that IBD slope may be a more robust correlate with dispersal scale than global $F_{\mathrm{ST}}$ with a new dataset of recent marine genetic studies. Re-evaluation of previously published and new datasets revealed a consistent, moderate fit $\left(\mathrm{R}^{2} \sim 0.30\right)$ between genetic and PLD proxies of dispersal (using either IBD slope or global $\left.F_{\mathrm{ST}}\right)$, with significant improvement for small-scale $(<650 \mathrm{~km})$ studies $\left(\mathrm{R}^{2}=0.50\right)$, and important effects of marker type. Significant effects of number of individuals and number of populations sampled on the genetic metrics in our dataset suggest a common need for more robust sampling designs. These results synchronize previous studies on this topic and provide validation that PLD and genetic metrics typically reflect scales of dispersal, as intended, at least when sampling design is robust.
\end{abstract}

KEY WORDS: Dispersal $\cdot F$-statistics $\cdot F_{\mathrm{ST}} \cdot$ Genetic structure $\cdot$ Isolation by distance $\cdot$ Marine connectivity $\cdot$ Pelagic larval duration $\cdot$ PLD

\section{INTRODUCTION}

Understanding scales of connectivity is crucial for basic and applied ecology of marine species, but appropriate and effective techniques to do so are limited. In the marine environment, dispersal often occurs during a larval or spore phase such that direct observation and mark-recapture are not feasible. Consequently, estimating rates, distances and patterns of dispersal with genetic metrics based on neutral molecular markers is a common practice in the study of marine connectivity. However, there is uncertainty regarding the overall performance of genetic estimates for this purpose and the conditions (e.g. taxa and study designs) under which the estimates are most reliable and informative (reviewed by Lowe \& Allendorf 2010). Due to a general lack of alternative methods to measure dispersal across a diversity of marine species, validating genetic estimates of dispersal is challenging (Levin 2006). However, a handful of recent studies assessed the correlation of genetic estimates of dispersal with estimates of pelagic larval duration (PLD, the length of time a larva spends in the water column after either hatching or spawning, before settlement to a fixed, often demersal habitat). These studies returned mixed results, ranging from very high correlation 
(Siegel et al. 2003) to virtually no relationship (Bradbury et al. 2008, Weersing \& Toonen 2009-hereafter W\&T). Our goal here is to investigate the reasons behind past conflicting results and build on them with new analyses that can explain their differences, provide new insights and highlight areas for future research. First we briefly summarize the foundations and assumptions behind PLD and genetic dispersal metrics and review current knowledge about marine larval dispersal in light of expectations of how genetic and PLD estimates of dispersal should compare.

\section{Genetic estimates of dispersal}

The most common metric for estimating dispersal distance with genetic markers, Wright's fixation index $\left(F_{\mathrm{ST}}\right)$, is a measure of genetic variation among a sample of geographically separated populations. The most basic $F_{\mathrm{ST}}$ calculation returns a single estimate for all sampled populations, hereafter termed 'global $F_{\mathrm{ST}}$.' Global $F_{\mathrm{ST}}$ describes the relative amount of genetic diversity held at the level of the population compared to the total diversity sampled, similar in concept to the partitioning of variation in an ANOVA. Under an 'island model' of dispersal, in which all populations contribute a certain percentage of offspring to a larval pool with homogenous redistribution to all populations (Fig. 1a), global $F_{\mathrm{ST}}$ relates to migration rate through

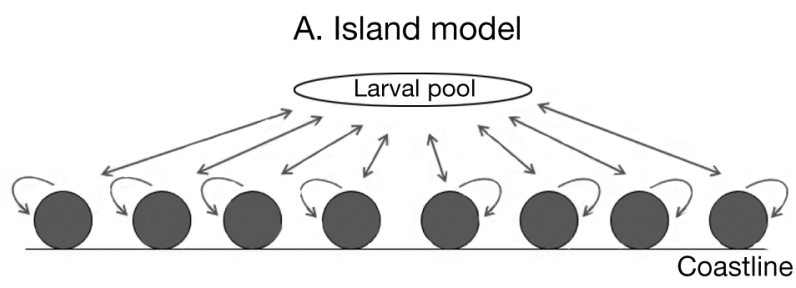

\section{B. Stepping stone model}



Fig. 1. Alternative models of dispersal. Circles represent populations along a coastline, which may or may not be straight. Arrows: larval migration. (A) Island model: all populations both self-recruit (i.e. larvae recruit to their natal population) and contribute equally to a well-mixed larval pool. The proportion of larvae received from the pool is the migration rate. (B) The stepping stone model: populations tend to exchange migrants with nearest neighbors, or populations at a set distance (e.g. 2 steps as shown here), which represents the average dispersal distance the equation $F_{\mathrm{ST}}=1 /\left(1+4 N_{\mathrm{e}} m\right)$, where $N_{\mathrm{e}}$ is effective population size, $m$ is migration rate and $N_{\mathrm{e}} m$ is effective number of migrants (Wright 1931, but see caveats in Whitlock \& McCauley 1999). This equation creates a negative linear relationship between $\log F_{\mathrm{ST}}$ and $\log m$ when $N_{\mathrm{e}}$ is held constant (Hellberg 1994). Because PLD is a proxy for dispersal distance, comparison of PLD and global $F_{\mathrm{ST}}$ requires that the migration rate is coupled to dispersal distance - an important assumption. It is important to note that migration rate is not synonymous with dispersal distance. Dispersal distance is the geographic distance traveled between source and settlement site, usually represented by a mean that averages across all individuals, including those that self-recruit and those that travel to other sites. Migration rate $(m)$ is the proportion of individuals that leave the natal site and successfully reproduce at another site.

A second commonly used genetic metric, the IBD slope, is derived from 'isolation-by-distance' (IBD) analysis, which uses $F_{\mathrm{ST}}$ calculated pairwise between all sampled populations (Wright 1943). Pairwise $F_{\mathrm{ST}}$ is calculated in the same way as global $F_{\mathrm{ST}}$, but using just 2 populations. Under a 'stepping stone model' of dispersal in which dispersal distance is less than the total extent of the sampled area (Kimura 1953; Fig. 1b), IBD theory suggests that pairwise $F_{\mathrm{ST}}$ will increase with the geographic distance between the pair of populations, creating a positive linear relationship that saturates at some distance (Rousset 1997, 2004 and citations therein). The IBD slope relates to the 'neighborhood size,' or variance in parent-offspring distance, and scales inversely with dispersal distance (Fig. 2). The saturation point may often occur at roughly twice the dispersal distance (Rousset 2004). If the saturation is not recognized in an empirical IBD plot and IBD slope is fit to points at all distances, the slope will be underestimated (and the dispersal distance overestimated).

\section{Isolation by distance}

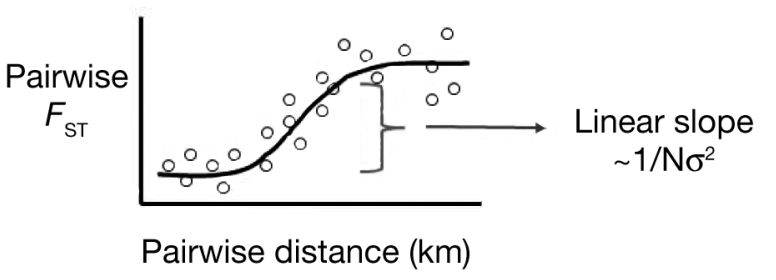

Fig. 2. Extracting a relative estimate of dispersal distance from an isolation-by-distance plot. Under stepping stone dispersal, pairwise $F_{\mathrm{ST}}$ increases linearly with pairwise distance between populations. $F_{\mathrm{ST}}$ starts at zero when samples are compared from the same population and similar location, subsequently $F_{\mathrm{ST}}$ shows a linear increase with distance at a small scale which saturates at some distance greater than twice the dispersal distance (Rousset 2004). The slope for the linear fit is inversely proportional to dispersal distance, represented by $\sigma^{2}$ (radius of parent-offspring distance). N: population density 
We feel that slope underestimation is likely common in the literature, because empirical sampling is often not dense enough to identify the point of saturation, and the vast majority of IBD studies fit slopes to all points with no assessment of saturation. However, focus in the empirical IBD literature is often not on accurate estimates of IBD slope values, but instead on simply testing whether the IBD slope is significantly $>0$, using a bootstrapping approach called a Mantel test. Nevertheless, because of the saturation phenomenon, IBD is likely underreported in the literature. Despite the nonlinearity of IBD, a log-log plot of dispersal distance and IBD slope has a negative linear relationship, the intercept of which is set by population density (Rousset 2004). Although there are other genetic approaches to estimating dispersal parameters, they are less common in the marine population genetics literature and are not covered here.

Using either global or pairwise $F_{\mathrm{ST}}$ to create a proxy for dispersal requires that effective population size $\left(N_{\mathrm{e}}\right)$ is uniform across populations, because calculations of dispersal based on $F_{\mathrm{ST}}$ represent the product of $N_{\mathrm{e}}$ and migration rate $\left(N_{\mathrm{e}} m\right)$. Conceptually, $N_{\mathrm{e}}$ represents population size in terms of genetic diversity; it is often approximated by the inverse of the geometric mean of census population size over recent $\left(10^{2}\right.$ to $\left.10^{3}\right)$ generations, which up-weights generations of small population size when diversity contracts (for more details see Frankham 1995 and Hare et al. in press). $F_{\mathrm{ST}}$ as a proxy for dispersal also assumes that dispersal patterns have been stable for many generations. After a disturbance and re-colonization event, both global $F_{\mathrm{ST}}$ and IBD slope typically increase in value through time until equilibrium is reached between the rate of genetic drift in the populations and the rate of migration between them (called drift-migration equilibrium); however, global $F_{\mathrm{ST}}$ is generally slower to reach equilibrium (Slatkin 1993, Bradbury \& Bentzen 2007). The number of generations needed to reach drift-migration equilibrium depends on $N_{\mathrm{e}}$, migration rate and the mutation rate of the markers, so it is hard to predict and will vary across species and studies, but evidence suggests the approach to equilibrium can be slow and, perhaps, can take 100s of generations (Whitlock \& McCauley 1999, Castric \& Bernatchez 2003). When using $F_{\mathrm{ST}}$ to estimate dispersal, one hopes populations are near drift-migration equilibrium so that values are reliable. When pairwise $F_{\mathrm{ST}}$ is found to increase with geographic distance, creating a statistically significant IBD slope, there is good reason to suspect that the basic assumptions of uniform $N_{\mathrm{e}}$ and equilibrium have been met or approached (Hutchison \& Templeton 1999). There is no such 'check' on whether the basic assumptions have been met for global $F_{\mathrm{ST}}$ without additional investigation (but see Bohonak \& Roderick 2001).

\section{Measuring pelagic larval dispersal scales}

PLD as a proxy for dispersal distance also has a long list of assumptions. In fishes, PLD is usually estimated from ring counts in the larval core of the otolith (i.e. earstone); rings are laid down only after egg hatching and so will underestimate total time in the plankton. The duration of the egg stage increases with latitude, which could create systematic bias in PLDs estimated from otolith ring counts (Bradbury et al. 2008). PLD is also often estimated from laboratory studies in which larvae are reared after fertilization, and the time until settlement is measured. There are many reasons that laboratory conditions may diverge from in situ conditions and lead to inaccurate estimates of PLD. In some cases, laboratory estimates could be biased downward because the experiment ends prematurely (i.e. larvae die), providing a minimum PLD instead of an average PLD. In other cases, however, larvae may be slow to settle because laboratory conditions do not provide the necessary settlement cues to induce metamorphosis out of the larval stage. Even in nature, many species have long pre-competent phases or plasticity in larval duration, often related to environmental conditions, that can create large variance in PLD within a species despite the common use of a single value based on comparatively few individuals (Toonen \& Pawlik 2001, O'Connor et al. 2007).

Aside from measurement error, PLD as a proxy for dispersal distance requires assumptions that larvae are passive particles and that flow is fairly uniform. Until recently, these assumptions were widely considered appropriate for marine systems, because the diffusive forces of the pelagic environment could impart a uniform, well-mixed distribution of larvae among all possible sources. Mean dispersal distance could then be estimated using PLD, rate of diffusion and mean current speed. Recent findings contrast sharply with this old paradigm. Once overlooked, foraging, aggregation and homing behaviors are now known to enhance the patchiness of larval distribution in the plankton (Paris et al. 2007, Pringle \& Wares 2007, Woodson \& McManus 2007, Leis et al. 2009, Morgan \& Fisher 2010, Pineda et al. 2010). Because hotspots of phytoplankton and prey are associated with meso-scale flow features like reversals, fronts and clines, all with net flows close to zero, once larvae enter these hotspots it is relatively easy to avoid transport. These flow features create cohesive water packets that reduce diffusion and mixing of larvae that come from distinct sources (Paris et al. 2007, Siegel et al. 2008, Mitarai et al. 2009, Shanks et al. 2010, Wright et al. 2009).

The net effects of these newly studied phenomena are reductions in the number of larval trajectories and the total dispersal distance - perhaps by 100 s of kilo- 
meters (Shanks 2009, Marshall et al. 2010). The new paradigm of marine larval dispersal focuses on a 'spiky dispersal kernel' (i.e. an irregular frequency distribution of larval dispersal pathways) that changes stochastically over time and space (Siegel et al. 2003, 2008) and may be very poorly represented by an estimate of PLD. However, the picture may change when a longterm view is taken. Variation in the timing and position of eddies and fronts will spread larvae and smooth out spiky dispersal kernels somewhat when averaged over multiple dispersal events. Periodic storm events promote sporadic large-scale mixing and transport, overriding larval behaviors that resist long-distance dispersal (Woodson \& McManus 2007). The effect of storm events on multi-generational averages of dispersal patterns may be a recovery of the signal of dispersal assumed under passive diffusion that scales with PLD, but may more accurately represent a maximum dispersal distance as storms tend to advect larvae farther and faster than normal. Genetic estimates of dispersal distance also reflect a long-term average of dispersal patterns. In sum, there is reason to believe that short-term and long-term characterizations of mean dispersal distance diverge and that PLD- and genetic-based estimates of dispersal may both best represent long-term average dispersal.

Shanks et al. (2003) and Shanks (2009) present the most comprehensive analysis to date of how well PLD predicts dispersal distance. By collecting independent, direct estimates of dispersal distance and comparing to propagule duration (a more general term that encompasses PLD), these studies found that at a gross scale, propagule duration was moderately correlated with dispersal distance $\left(\mathrm{R}^{2}=0.48, \mathrm{p}<0.00001, \mathrm{n}=64\right.$; Shanks 2009). Note the dataset necessarily focused on species for which dispersal distance could be estimated either by direct observation or tracking colonization fronts of invasive species, which come with particular biases and cannot be generalized to other life-history types. All points fell below a regression line representing passive dispersal in a steady flow of $10 \mathrm{~cm} \mathrm{~s}^{-1}$, and almost all points fell below a regression line representing passive dispersal in the particletracking model of dispersal by Siegel et al. (2003). These results imply that PLD measurement bias or retentive forces, such as swimming and/or flow complexities, reduce dispersal below what would be expected of passive transport. The key message is that despite the strong predictive power of PLD, it is best used to set an upper bound on dispersal distance, not a mean dispersal distance, which fits with the new paradigm above. Furthermore, for the 53 points with PLD $>1 \mathrm{~d}$, there is a very weak relationship to dispersal distance (Shanks 2009), suggesting that directdeveloping species with very short dispersal distances are driving the stronger correlation. However, PLD remains the most widely available proxy metric of dispersal for marine species with which to assess the performance of genetic estimates of dispersal. If PLD and genetic estimates do not agree, it suggests there are either large measurement errors or other poorly understood forces decoupling the 2 that warrant further investigation to hone these tools or decide to discard them.

\section{REVIEW OF THE EVIDENCE}

Despite many assumptions behind both genetic and PLD dispersal estimates, they are by far the most widely used proxies of dispersal. Over the past decade, many studies attempted to cross validate the 2 approaches by synthesizing empirical work. The earliest review on this topic, by Bohonak (1999), confirmed the basic expectation that a more dispersive larval form is associated with lower genetic differentiation within many taxonomic groups. Subsequent studies (see Table 1) compared PLD and $F_{\mathrm{ST}}$ at finer resolution, and have reported mixed results, with some highly significant relationships and multiple tests finding only a weak relationship (i.e. $\mathrm{R}^{2}<0.15$ ). Here we investigate the similarities and differences across these past studies to examine how sampling, study design and choice of metrics may play into the correlations reported between PLD and the genetic proxies of dispersal.

Siegel et al. (2003) reported the strongest correlation of genetic and PLD estimates of dispersal for a comparison of 32 species $\left(R^{2}=0.80\right.$; Table 1$)$. Importantly, their study used IBD slopes as a basis for the genetic estimate. IBD slope was first exponentially transformed to a geographic distance using the equation


ulating stepping stone dispersal with demographic parameters thought to be generally appropriate for marine species (Palumbi 2003). While this exponential transformation was later shown to be less reliable than other exponential formulations for extrapolating dispersal distance from IBD slope (Gomez-Uchida \& Banks 2005, Bradbury \& Bentzen 2007), the raw slope data gave the same correlation with PLD as the transformed values. When global $F_{\mathrm{ST}}$ values taken from these same studies were compared to PLD, no relationship existed $\left(R^{2}=0.00 ; \mathrm{W} \& \mathrm{~T}\right)$. The correlation between global $F_{\mathrm{ST}}$ and PLD remained weak when W\&T took a much larger set of 149 studies reporting global $F_{\mathrm{ST}}$ for which PLD estimates were also available, although the large sample size resulted in statistical significance $\left(\mathrm{R}^{2}=0.10\right.$; Table 1$)$. They reported that, compared to larval duration, genetic marker type (i.e. mitochondrial sequence data, allozyme or nuclear microsatellites) 
Table 1. Summary of approaches and results of past studies testing the correlation between pelagic larval duration (PLD) and $F_{\mathrm{ST}}$-based measures of population structure. IBD: isolation by distance; NA: not available

\begin{tabular}{|c|c|c|c|c|c|c|c|c|c|c|}
\hline \multirow[t]{2}{*}{ PLD data } & \multirow[t]{2}{*}{$\begin{array}{c}F_{\mathrm{ST}} \\
\text { metric }\end{array}$} & \multirow[t]{2}{*}{$\begin{array}{l}\text { Transformation } \\
\text { of } F_{\mathrm{ST}} \text { data }\end{array}$} & \multirow[t]{2}{*}{ Focus } & \multicolumn{3}{|c|}{$\begin{array}{l}F_{\text {ST }} \text { vs. PLD } \\
\text { correlation }\end{array}$} & \multicolumn{3}{|c|}{$\begin{array}{l}F_{\text {ST Vs. PLD }} \\
\text { PLD }>0 \text { only }\end{array}$} & \multirow[t]{2}{*}{ Source } \\
\hline & & & & $\mathrm{R}^{2}$ & $\mathrm{p}$ & $\mathrm{N}$ & $\mathrm{R}^{2}$ & $\mathrm{p}$ & $\mathrm{N}$ & \\
\hline $\begin{array}{l}\text { Log of } \\
\quad \text { mean PLD }\end{array}$ & IBD slope & $\begin{array}{l}\text { Exponential } \\
\text { after Palumbi } \\
\text { (2003), then log }\end{array}$ & $\begin{array}{l}\text { Demersal marine } \\
\text { species showing } \\
\text { IBD }\end{array}$ & 0.80 & $<0.0001$ & 32 & 0.43 & 0.0002 & $27^{\mathrm{a}}$ & Siegel et al. (2003) \\
\hline $\begin{array}{l}\text { Mean PLD } \\
\text { of taxon }\end{array}$ & $\begin{array}{l}\text { Mean residual } \\
\text { global } F_{\mathrm{ST}} \\
\text { of taxon }\end{array}$ & $\begin{array}{l}\text { Residuals taken } \\
\text { from a linear fit } \\
\text { of log of } F_{\mathrm{ST}} \text { to log } \\
\text { of max. pairwise } \\
\text { geographic } \\
\text { distance }\end{array}$ & $\begin{array}{l}\text { Invertebrate } \\
\text { and fishes: } \\
\text { phyla or class } \\
\text { level; fishes } \\
\text { only: family } \\
\text { level }\end{array}$ & 0.15 & $\begin{array}{c}\text { All: } \\
0.15 \\
\text { Fishes: } \\
0.36\end{array}$ & 10 & \multicolumn{3}{|c|}{ NA } & $\begin{array}{l}\text { Bradbury et al. } \\
(2008)\end{array}$ \\
\hline $\begin{array}{l}\log (x+1) \\
\text { of mean PLD; } \\
\text { also tested } \\
\text { min. and } \\
\text { max. PLD }\end{array}$ & $\begin{array}{c}\text { Global } \\
F_{\mathrm{ST}}\end{array}$ & $\log (x+1)$ & $\begin{array}{l}\text { Demersal, } \\
\text { sexually } \\
\text { reproducing } \\
\text { marine species }\end{array}$ & $0.10^{N}$ & $\begin{array}{l}\text { Mean PLD } \\
<0.000 \\
\text { Max. PLD } \\
<0.0001\end{array}$ & 149 & $0.03^{N}$ & $\begin{array}{c}\text { Iean PL } \\
0.053 \\
\\
\text { Iax. PLD } \\
0.01\end{array}$ & 135 & $\begin{array}{l}\text { Weersing \& } \\
\text { Toonen (2009) }\end{array}$ \\
\hline $\begin{array}{l}\text { Max. PLD } \\
\text { estimate }\end{array}$ & Global $F_{\mathrm{ST}}$ & $\begin{array}{l}\text { Natural } \\
\log \end{array}$ & $\begin{array}{l}\text { Marine species } \\
\text { sampled in } \\
\text { New Zealand }\end{array}$ & 0.39 & $<0.01$ & 29 & 0.13 & 0.10 & 21 & Ross et al. (2009) \\
\hline Mean PLD & Global $F_{\mathrm{ST}}$ & None & $\begin{array}{l}\text { Nearshore inverte- } \\
\text { brates sampled on } \\
\text { the Pacific coast of } \\
\text { North America }\end{array}$ & 0.13 & 0.011 & 50 & 0.00 & 0.95 & 41 & $\begin{array}{l}\text { Kelly \& Palumbi } \\
(2010)\end{array}$ \\
\hline $\begin{array}{l}\log (x+0.1) \\
\text { of mean PLD }\end{array}$ & Global $F_{\mathrm{ST}}$ & Log-linear ${ }^{c}$ & $\begin{array}{l}\text { Demersal coastal } \\
\text { fish species }\end{array}$ & \multicolumn{3}{|c|}{$\begin{array}{l}\text { Not significant } \\
\text { statistics NA }\end{array}$} & \multicolumn{3}{|c|}{$\begin{array}{l}\text { Not significant; } \\
\text { statistics NA }\end{array}$} & $\begin{array}{l}\text { Riginos et al. } \\
\text { (2011) }\end{array}$ \\
\hline
\end{tabular}

was a better predictor of $F_{\mathrm{ST}}$ than PLD. The key difference between the approaches of Siegel et al. (2003) and W\&T was the use of global $F_{\mathrm{ST}}$ versus the IBD slope, implying that the correlation between global $F_{\mathrm{ST}}$ and the IBD slope could only be poor to moderate. Indeed, comparing the global $F_{\mathrm{ST}}$ estimates to the IBD slopes for the 22 studies included in the appendices of both Siegel et al. (2003) and W\&T showed no correlation between the two sets of values $\left(R^{2}=0.02\right)$. However, theory suggests these values should correlate at least moderately, and we revisit the source of this inconsistency later.

Like W\&T, the remaining 4 studies of the correlation between PLD and genetic estimates of dispersal focused on global $F_{\mathrm{ST}}$, because it is more widely available than IBD slope. These studies generally corroborated the low correlation found by W\&T, despite important methodological differences (Table 1). Bradbury et al. (2008) assessed the global $F_{\text {ST }}$ versus PLD correlation, but $F_{\mathrm{ST}}$ was first transformed by taking the residual value from a linear regression of $F_{\mathrm{ST}}$ on maximal sampling distances under the assumption that sampling scale influences $F_{\mathrm{ST}}$. Analysis of $F_{\mathrm{ST}}$ versus PLD correlation for marine fishes was reported simply as not significant (Bradbury et al. 2008). However, their paper mainly focused on using the mean $F_{\mathrm{ST}}$ and mean PLD of higher taxonomic groups, including fishes, invertebrates and algae, instead of analysis at the species level. The strength of the $F_{\mathrm{ST}}$ versus PLD correlation was similar to that in W\&T, but not significant (Table 1). The data showed a bimodal distribution, with echinoderms, fishes and crustaceans clustering towards low mean $F_{\mathrm{ST}}$ and high PLD, and all other taxa showing low PLD with a range of mean $F_{\mathrm{ST}}$ values. The authors also collected other dispersal-related lifehistory information, and found that latitude, adult body size and the proportion of species with demersal eggs were all significant predictors of $F_{\mathrm{ST}}$ (Bradbury et al. 2008). These results beg the question of whether PLD, a more difficult metric to estimate, actually provides more precise predictive power about dispersal capability beyond easier-to-measure traits such as egg type, latitude and body size.

Like Bradbury et al. (2008), Riginos et al. (2011) analyzed many life-history traits, and reported that egg type (benthic vs. pelagic) is a better predictor of global $F_{\text {ST }}$ than PLD, but also found that whether a study spans a biogeographic boundary is a slightly better 
predictor. Their study focused just on marine fishes, and used species-level analysis of global $F_{\mathrm{ST}}$ versus PLD. The data corroborated the effect of marker type on $F_{\mathrm{ST}}$ found by W\&T, as well as the effect of study scale reported by Bradbury et al. (2008). PLD emerged as a significant predictor only when Riginos et al. (2011) categorized fishes by family; Labridae was the only 1 of 4 families tested to show a significant $F_{\mathrm{ST}}$ versus PLD correlation across species, with moderate explanatory power $\left(R^{2}=0.37\right.$; Table 1$)$. Because of the low sample size, the p-value of 0.04 reported for this relationship becomes non-significant using a familywide $\mathrm{p}$-value correction (the other 3 families tested are considered as replicates); therefore, the Labridae trend cannot be considered robust (Benjamini \& Hochberg 1995). A higher sample size could reveal that a correlation exists. A similar level of $F_{\mathrm{ST}}$ versus PLD correlation was reported by Ross et al. (2009), which focused on 29 species of mostly crustaceans, mollusks and echinoderms in New Zealand waters $\left(R^{2}=0.39\right.$; Table 1$)$. However, when the 8 species with PLD values of zero are removed, the trend loses significance. W\&T and Riginos et al. (2011) also found that when directdeveloping species $(\mathrm{PLD}=0$ ) were removed, the positive trends in the relationship weakened (Table 1). Lastly, a study of 50 intertidal species along the west coast of the USA also found no relationship between $F_{\mathrm{ST}}$ and PLD unless brooding species were included (Kelly \& Palumbi 2010). Instead, latitude and depth covaried more strongly with $F_{\mathrm{ST}}$ i however, the authors reported strong taxonomic and sampling biases in the dataset, suggesting such trends should be interpreted with caution (Kelly \& Palumbi 2010).

In sum, 5 studies of global $F_{\mathrm{ST}}$ versus PLD uniformly show low explanatory power and/or lack of significance. Results were generally similar whether made at the species level or when species were lumped into higher taxonomic groups. Much of the explanatory power comes from the comparison of non-pelagic species (PLD $<1 \mathrm{~d}$ ) with pelagic species, suggesting that easier-to-measure traits like larval type and egg type may provide similar levels of predictive power as PLD in explaining differences in global $F_{\mathrm{ST}}$ across studies. In contrast to these 5 studies based on global $F_{\mathrm{ST}}$, only 1 study used IBD slope to compare genetic and PLD estimates of dispersal (Siegel et al. 2003); their study showed high explanatory power, but with a fairly small sample size. Based on this imbalance in the literature, there is little reason to continue testing for any relationship between global $F_{\mathrm{ST}}$ and PLD in future studies, and good reason to attempt to confirm the strong correlation between IBD-based and PLD-based estimates of dispersal.

As mentioned above, there is some reason to believe that IBD-based estimates should have a stronger correlation with PLD than global $F_{\mathrm{ST}}$ (Palumbi 2003). First, IBD slope relates directly to dispersal distance, whereas $F_{\text {ST }}$ provides a metric of genetic differentiation from which migration rate, not dispersal distance, can be inferred. Second, finding a significant IBD slope is consistent with approximate drift-migration equilibrium and uniform population size among samples. However, finding a significant IBD slope is far from ubiquitous in studies of marine species with pelagic larvae. Limiting the empirical genetic studies to those showing significant IBD slopes should select for situations in which the stepping stone model applies, indicating that the flow fields which carry larvae are uniform. A uniform flow field is also the oceanographic setting in which PLD should be a good estimate of dispersal distance. Based on these distinctions between IBD and global $F_{\mathrm{ST}}$, we tested the hypotheses that IBD slopes provide better correlation with PLD than global $F_{\mathrm{ST}}$ values by creating a new database focused on studies that explicitly tested for IBD, and compared correlations of IBD slope and global $F_{\mathrm{ST}}$ with PLD, while also exploring the influence of study scale and marker type on the correlations.

\section{MATERIALS AND METHODS}

We used a Web of Science (WoS) search with the terms 'marine' and 'isolation by distance' to identify a pool of studies from which to gather data on the relationship between PLD, $F_{\mathrm{ST}}$ and IBD. Our focus was limited to marine species with benthic adult stages; anadromous species and obligate estuarine species were excluded, as were marine species with migratory adults or juveniles. We examined 167 studies identified by the WoS and published between 2002 and October 2010. Certainly some studies that tested for IBD are missed by these search terms; however, this approach allowed us to reach a sample size with enough power to test our hypotheses. We also searched for population genetic studies of additional species for which we already had compiled estimates of PLD, by searching the species name and the term 'genetic' on the WoS. PLD estimates came from databases created by previous reviews (Shanks et al. 2003, Siegel et al. 2003, Lester et al. 2007, Shanks 2009, W\&T) or were reported with citations in the genetic studies.

The primary criteria for including a study in our database were the existence of both a verifiable, referenced PLD estimate for the study species and a Mantel test of the correlation of pairwise $F_{\mathrm{ST}}$ and pairwise geographic distance. Studies were sorted into 2 groups: those with statistically significant Mantel tests $(p<$ 0.05, 'IBD dataset') and those with non-significant Mantel tests ( $p>0.05$, 'No IBD dataset'). Studies were 
excluded when: IBD slope was based on $<4$ populations, microsatellite or allozyme studies used $<4$ markers, studies were based on 'RAPD' markers, studies showed strong clines in diversity across the study region (perhaps inflating the IBD signal) and studies for which neither global $F_{\mathrm{ST}}$ nor IBD slope were significantly different from zero. Unfortunately, the depth of reporting on estimates of PLD varies widely, and availability of PLD was the limiting factor in building the database. We could think of no systematic way to screen PLD estimates for error and quality without drastic loss of sample size and so all are included here. For studies which met the criteria for inclusion, up to 22 attributes of the species, study design and results were included in the database for each study, when available (see Table $\mathrm{S} 1$ in the supplement at www.intres.com/articles/suppl/m436p291_supp.pdf). IBD slopes were taken either from reported values, extracted from slopes included on IBD plots, or calculated from pairwise $F_{\mathrm{ST}}$ and geographic distance data available from tables and maps using ordinary least squares (OLS) regression. Although reduced major axis (RMA) regression is more appropriate (Hellberg 1994), OLS slopes were more common in published figures and using RMA instead of OLS where possible had no effect on results. In a few cases, studies tested for IBD with appropriate methods, and reported a significant p-value but provided no slope, pairwise $F_{\mathrm{ST}}$ values, or IBD plot with which to extract the IBD slope. If the study included a global $F_{\mathrm{ST}}$ value and significant Mantel p-value, they were included in the IBD dataset without IBD slope information, so that at least the global $F_{\mathrm{ST}}$ value could be used.

If a single study found $>1$ significant IBD slope value by doing separate IBD analyses at different spatial scales, the smaller scale slope was used according to the rationale that IBD is a phenomenon that occurs at local scales (Rousset 2004). In some studies, IBD slope was derived for a subset of populations sampled. When the study reported cause for suspecting a different drift-migration equilibrium for the excluded populations (e.g. recent bottleneck or hybridization with a sister taxon at the site) or when the excluded populations were spatially isolated from the rest of the study domain, these slopes based on subsets were used. If there was no biological rationale for forming the subset, the study was excluded. Some slope data were derived from plots of an estimate of migration rate $(\hat{m})$ versus geographic distance, as in Slatkin (1993). These were included when the $\hat{m}$ data could be converted to pairwise $F_{\mathrm{ST}}$ values and the relationship of pairwise $F_{\mathrm{ST}}$ versus geographic distance produced Mantel $\mathrm{p}<0.05$. IBD slopes based on estimates of genetic differentiation other than $F_{\mathrm{ST}}$ were excluded (e.g. Nei's $D$ or Roger's distance).
From the database, correlations of several attributes were examined. PLD, $F_{\mathrm{ST}}$ and slope values were first $\log _{10}$ transformed before analyses. The raw data in the Siegel et al. (2003) and W\&T datasets, which were available in their appendices, were also given the same transformations to make their results more comparable to those here. W\&T's data were originally analyzed after $\log (x+1)$ transformation. Log transformations of the raw PLD and $F_{\mathrm{ST}}$ data created better normality (i.e. less skew due to fewer outliers) than the $\log (x+1)$ transformation, but required that the 10 studies for which $F_{\mathrm{ST}}=0$ were removed. Using the log transformation had a minor effect on the main analysis reported in W\&T, i.e. PLD versus $F_{\mathrm{ST}}\left(\mathrm{R}^{2}=0.12, \mathrm{p}<\right.$ $0.0001, \mathrm{n}=139$ ).

Statistical significance of cross-species correlations was assessed with univariate OLS regression or multivariate generalized linear models (GLM) using normal distribution and identity link function in the software program JMP. Confidence intervals on correlation coefficients were generated by bootstrapping in the software program R. Akaike's information criterion $\left(\mathrm{AIC}_{\mathrm{C}}\right)$ was used to select the most parsimonious models for multivariate cases.

\section{RESULTS}

\section{Description of the IBD dataset}

Fifty-five data points were included in our IBD dataset, taken from 48 studies, and representing 50 species: 21 fishes, 20 mollusks, 3 cnidarians, 2 echinoderms, 1 crustacean and 3 algae. The oldest studies were from 1997 , and the median study year was 2007 (Table 2). Twentysix studies were based on microsatellites, 20 were based on mitochondrial DNA sequence (Cytochrome $c$ oxidase subunit $1=11$, Cytochrome $\mathrm{B}=4$, control region $=6$ ), 7 were based on allozymes, 1 used amplified fragmentlength polymorphism, and 1 used nuclear restriction fragment-length polymorphism. Twelve species were included with no pelagic larval phase; they are considered direct developers ( 6 fish, 4 mollusks and 1 alga). The mean PLD for the remaining 43 species was $32.6 \mathrm{~d}$, median PLD was $17.7 \mathrm{~d}$, and the values ranged from 1.1 to 182 d. Europe (including the Atlantic, Mediterranean, North Sea and Baltic coasts) was the best represented geographic region in the dataset; the rest of the studies were scattered throughout the world's oceans, except for polar regions.

Of the 55 data points, 12 were missing IBD slope values, and were used only for global $F_{\mathrm{ST}_{\mathrm{T}}}$-based analyses. Of the remaining 43, ten IBD slopes were based on 2 dimensional (2D) sampling arrays, and the rest were either entirely or mostly 1D. Slopes from 2D arrays 
Table 2. Characteristics of the datasets compared in the present study. PLD: pelagic larval duration; IBD: isolation by distance; NA: not available

\begin{tabular}{|c|c|c|c|c|}
\hline Summary statistics & $\begin{array}{c}\text { Siegel } \\
\text { et al. } \\
(2003)\end{array}$ & $\begin{array}{l}\text { Weersing } \\
\text { \& Toonen } \\
\text { (2009) }\end{array}$ & $\begin{array}{c}\text { IBD } \\
\text { dataset }\end{array}$ & $\begin{array}{l}\text { No IBD } \\
\text { dataset }\end{array}$ \\
\hline Total sample size & 32 & 139 & 55 & 31 \\
\hline Number of species & 32 & 122 & 50 & 29 \\
\hline Number of fishes & 12 & 68 & 21 & 8 \\
\hline Number of mollusks & 7 & 22 & 20 & 11 \\
\hline Number of studies & $29^{a}$ & 86 & 48 & 28 \\
\hline Median study year & 1997 & 2000 & 2007 & 2008 \\
\hline $\begin{array}{l}\text { Percent microsatellite } \\
\text { studies }\end{array}$ & 0.03 & 0.21 & 0.47 & 0.55 \\
\hline $\begin{array}{l}\text { Percent mtDNA } \\
\text { studies }\end{array}$ & 0.09 & 0.26 & 0.36 & 0.26 \\
\hline $\begin{array}{l}\text { Percent allozyme } \\
\text { studies }\end{array}$ & 0.75 & 0.53 & 0.13 & 0.16 \\
\hline $\begin{array}{l}\text { Percent non pelagic } \\
\text { developers }\end{array}$ & 0.00 & 0.17 & 0.22 & 0.10 \\
\hline $\begin{array}{l}\text { Mean PLD of pelagic } \\
\text { developers }\end{array}$ & 23.7 & 32.4 & 32.6 & 63.4 \\
\hline $\begin{array}{l}\text { Median PLD of } \\
\text { pelagic developers }\end{array}$ & 15.5 & 25 & 17.7 & 41 \\
\hline $\begin{array}{l}\text { Percent 1D IBD } \\
\text { sampling arrays }\end{array}$ & NA & NA & 0.78 & 0.61 \\
\hline $\begin{array}{l}\text { Mean study scale } \\
\text { extent }(\mathrm{km})\end{array}$ & NA & 2613 & 2710 & 3674 \\
\hline Mean global $F_{\mathrm{ST}}$ & $0.08^{\mathrm{b}}$ & 0.15 & 0.13 & 0.07 \\
\hline Median global $F_{\mathrm{ST}}$ & $0.05^{\mathrm{b}}$ & 0.05 & 0.04 & 0.02 \\
\hline
\end{tabular}

were slightly but not significantly lower than the 1D slopes on average. IBD plots were mostly based on regression of linearized $F_{\mathrm{ST}}\left(F_{\mathrm{ST}} /\left[1-F_{\mathrm{ST}}\right]\right)$ on raw geographic distance in kilometers, and, when possible, all slopes were calculated based on this format because the majority of studies were 1D and it was preferable to have all slopes with the same units for comparability. However, 10 data points used untransformed $F_{\mathrm{ST}}$, and 4 used the $\log$ of distance versus linearized $F_{\mathrm{ST}}$. Six studies reported no global $F_{\mathrm{ST}}$ value. Because the other data showed a strong relationship between global $F_{\mathrm{ST}}$ and mean pairwise $F_{\mathrm{ST}}$, an estimate of global $F_{\mathrm{ST}}$ was used for these 6 based on the linear fit (global $F_{\mathrm{ST}}=$ $1.38 \times$ mean pairwise $\left.F_{\mathrm{ST}}-0.005, \mathrm{R}^{2}=0.88, \mathrm{p}<0.0001\right)$. Including these data, global $F_{\mathrm{ST}}$ ranged from 0.00013 to 0.89 , with a median value of 0.04 and a mean value of 0.13 ; excluding these 6 data had no impact on the inferences drawn here.

\section{Comparison with Siegel et al. (2003) dataset}

Our first analysis addressed the question of whether the new IBD dataset would corroborate the results of
Siegel et al. (2003) by showing a strong correlation between IBD slope and PLD (hereafter termed PLD vs. IBD). Siegel et al. (2003) included 32 species in their dataset, and reported $\mathrm{R}^{2}=0.80$ for PLD versus IBD. Although their reported results focused on a simulation-derived exponential transformation of IBD slope to an estimate of average dispersal scale in kilometers, a $\log _{10}$ transformation of the raw IBD slope data provided in their appendix gives an identical fit. However, error-checking their PLD data revealed that 5 species that were assigned PLD = $0.17 \mathrm{~d}$ actually have a PLD of 1 to $2 \mathrm{~d}$ ( 4 of these are brooding corals with PLD information stemming from Ayre \& Hughes 2000). Log of 1.5 is 0.17, explaining this erroneous value. We also assigned a species with a larval phase of 1 to $4 \mathrm{~h} \log$ PLD $=0$ instead of $\log$ PLD $=-0.82$ to avoid creating an outlier in the distribution of PLD values, and because 1 to $4 \mathrm{~h}$ can be rounded to $0 \mathrm{~d}$ (Celleporella hyaline; Goldson et al. 2001). With these changes, the fit of the PLD versus IBD relationship from the Siegel et al. dataset was slightly less $\left(\mathrm{R}^{2}=0.70 ;\right.$ Fig. 3A). Our IBD dataset also produced a significant relationship for PLD versus IBD, but the fit was much weaker $\left(\mathrm{R}^{2}\right.$ $=0.34, \mathrm{p}<0.0001$; Fig. 3B, Table 3), and bootstrapped confidence intervals on the correlation coefficients from the 2 datasets were non-overlapping (Siegel et al. dataset: $r=-0.84[-0.90,-0.70]$; new IBD dataset: $r=-0.58[-0.69,-0.34])$. When the 8 direct developers were excluded from our dataset, the fit worsened $\left(\mathrm{R}^{2}=0.28, \mathrm{p}=0.0008\right.$; Table 2$)$.

Comparing the 2 plots in Fig. 3 highlights the greater variance in IBD slope values at low PLD in the new IBD dataset relative to the Siegel et al. (2003) dataset. Siegel et al. drew 4 of their 6 low PLD data points from Ayre \& Hughes (2000), and these 4 points cluster tightly together and have high leverage on the linear fit. These 4 species are all brooding corals sampled in the same locations, and so they represent little taxonomic or geographic diversity, explaining their high similarity and suggesting that the correlation strength may be inflated $\left(\mathrm{R}^{2}\right.$ drops from 0.70 to $\sim 0.60$ when the 4 brooding corals are treated as a single data point).

We sought to understand further the differences between the datasets by examining the original references used by Siegel et al. (2003). While 8 species were common to both datasets, the IBD slope value used for the species differed by an order of magnitude between the studies for 6 of the 8. The discrepancies were largely due to the fact that two-thirds of the data points in the Siegel et al. (2003) study were not actually based on a conventional IBD slope. Two other ways of deriving a genetic estimate of dispersal distance were used as a surrogate for an IBD slope to be able to include species for which an IBD study did not exist. As ex- 

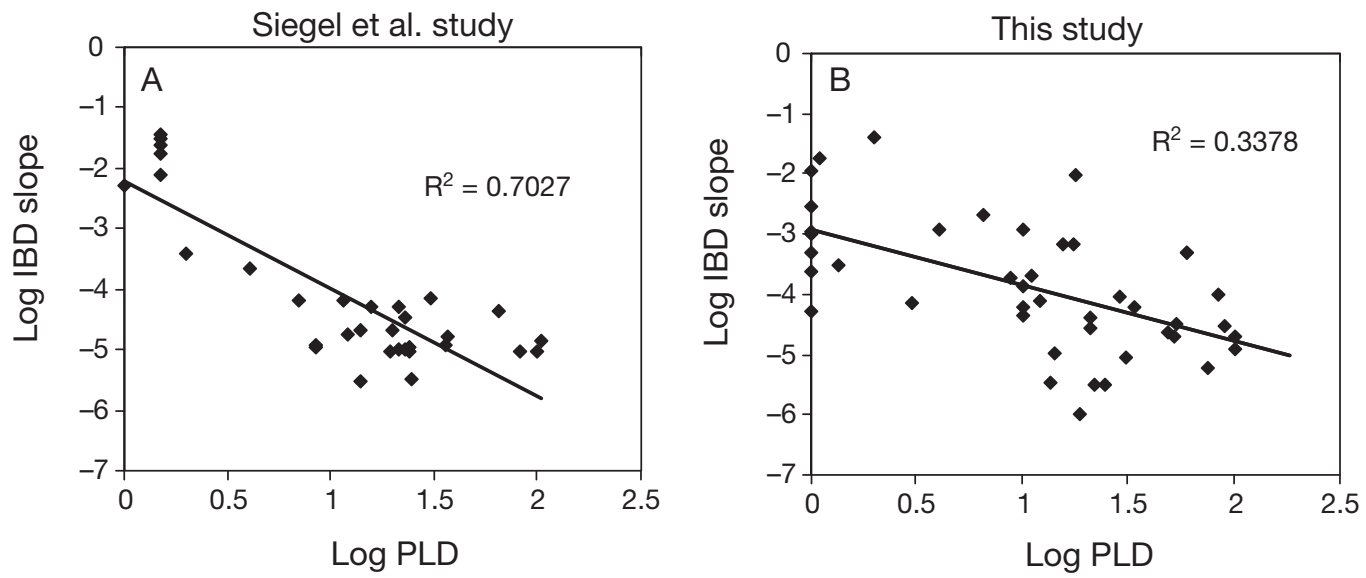

Fig. 3. Plot of log pelagic larval duration (PLD) versus log isolation-by-distance (IBD) slope from 2 distinct datasets: (A) 32 species from the dataset by Siegel et al. (2003) and (B) 44 species from the present IBD dataset

plained in the methods of Kinlan \& Gaines (2003), 2 or more hierarchical $F_{\mathrm{ST}}$ values at increasing spatial scales were used to calculate a slope (hereafter termed hierarchical $F_{\mathrm{ST}}$ ), or a single global $F_{\mathrm{ST}}$ value was divided by the maximum pairwise geographic distance to calculate a slope (hereafter termed $F_{\mathrm{ST}} / \mathrm{km}$ ). In sum, there were large differences in the methodologies and sample pools of the 2 datasets.

We sorted the Siegel et al. (2003) data by the 3 methods of slope derivation, and analyzed the categories separately. For the 10 data points based on a true IBD slope, the PLD versus IBD fit dropped $\left(\mathrm{R}^{2}=0.49, \mathrm{p}=\right.$ $0.001)$, although it was still stronger than our finding $\left(\mathrm{R}^{2}=0.34\right)$. The 12 data points based on $F_{\mathrm{ST}} / \mathrm{km}$ showed the best fit $\left(\mathrm{R}^{2}=0.88, \mathrm{p}<0.0001\right)$. The 10 data points based on hierarchical $F_{\mathrm{ST}}$ values also showed a good fit to PLD $\left(\mathrm{R}^{2}=0.65, \mathrm{p}=0.0004\right)$.

We then divided the global $F_{\mathrm{ST}}$ values in our IBD dataset by the maximum pairwise geographic distance in the study to get $F_{\mathrm{ST}} / \mathrm{km}$, as in Siegel et al. (2003), and found an improvement in the fit with PLD over using the IBD slopes $\left(\mathrm{R}^{2}=0.60\right.$, compared to $\left.\mathrm{R}^{2}=0.34\right)$. We added data for 12 additional studies that reported significant IBD Mantel tests and global $F_{\mathrm{ST}}$ but did not provide adequate data for extraction of the IBD slope values. The fit was unchanged $\left(\mathrm{R}^{2}=0.61\right.$; Fig. $4 \mathrm{~A}$, Table 3). The fit dropped a bit when the 12 direct developers were removed $\left(\mathrm{R}^{2}=0.54\right.$; Table 3$)$. Not surprisingly, $F_{\mathrm{ST}} / \mathrm{km}$ was correlated with IBD slope $\left(\mathrm{R}^{2}=\right.$ 0.56, $\mathrm{p}<0.0001$ ). Because maximum pairwise geographic distance is often a characteristic of the study design and not of biology - at least at distances less than the total species range-we thought it was important to explore its role in driving the improved correlation of $F_{\mathrm{ST}} / \mathrm{km}$ with PLD. An alternative way to account for both PLD and study scale, as predictor vari- ables in a GLM for global $F_{\mathrm{ST}}$, showed both variables to be highly significant ( $p<0.001$ ). Maximum pairwise geographic distance itself is significantly correlated with PLD, but only when direct developers were excluded $\left(\mathrm{R}^{2}=0.16\right.$ with vs. 0.27 without direct developers). Global $F_{\mathrm{ST}}$ alone showed a lower but still significant correlation with PLD $\left(\mathrm{R}^{2}=0.38\right.$; Fig. $\left.4 \mathrm{C}\right)$ that dropped when the 12 direct developers were excluded $\left(\mathrm{R}^{2}=0.21\right.$; Table 3$)$.

In sum, our IBD dataset showed that IBD slope had a significant, but more modest correlation with PLD $\left(\mathrm{R}^{2}=\right.$ 0.34) than reported previously. Global $F_{\mathrm{ST}}$ showed a similar correlation $\left(\mathrm{R}^{2}=0.38\right)$, but when global $F_{\mathrm{ST}}$ was standardized by study scale, the correlation with PLD almost doubled $\left(\mathrm{R}^{2}=0.60\right)$. When direct developers are excluded, all of these fits drop by from 10 to $40 \%$.

\section{Comparison with W\&T dataset}

W\&T found that marker type was a significant covariate and interaction term with PLD when modeling global $F_{\mathrm{ST}}$. This finding was corroborated by Riginos et al. (2011). Therefore, we used a GLM to assess the role of marker type in the correlation of global $F_{\mathrm{ST}}$ with PLD (hereafter PLD vs. $F_{\mathrm{ST}}$ ) analysis for our IBD dataset for comparison to results of W\&T. The effect of marker type significantly improved the model fit over the simple PLD vs. $F_{\mathrm{ST}}$ regression (IBD: $\mathrm{R}^{2}=0.56, \mathrm{p}<$ $\left.0.0001, \Delta \mathrm{AIC}_{\mathrm{c}}=3.4\right)$, as it did for W\&T $\left(\mathrm{R}^{2}=0.40, \mathrm{p}<\right.$ $\left.0.0001, \Delta \mathrm{AIC}_{\mathrm{c}}=50.4\right)$. Excluding direct developers slightly reduced the fit for our dataset, but not for W\&T (IBD: $\mathrm{R}^{2}=0.41 ; \mathrm{W} \& \mathrm{~T}: \mathrm{R}^{2}=0.43$ ). Marker type as a covariate failed to improve the model fit for the correlations of IBD slope or $F_{\mathrm{ST}} / \mathrm{km}$ with PLD for our IBD dataset. 

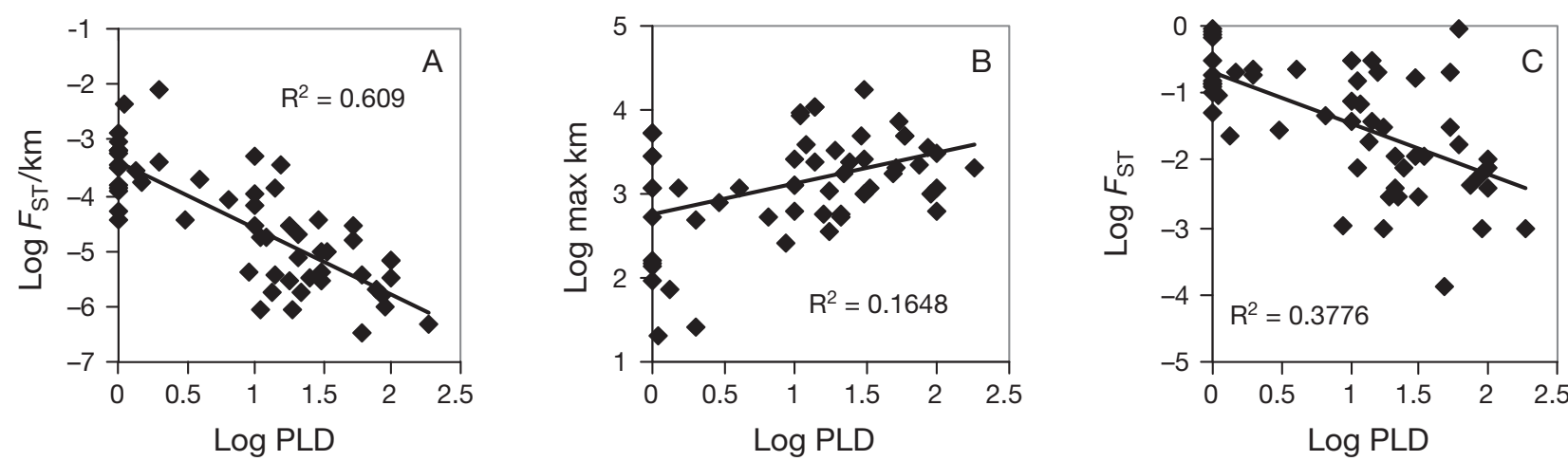

Fig. 4. Data from the IBD dataset. $F_{\mathrm{ST}}$ refers to global $F_{\mathrm{ST}}$. (A) Log pelagic larval duration (PLD) versus log $F_{\mathrm{ST}}$ divided by maximum study distance $\left(F_{\mathrm{ST}} / \mathrm{km}\right)$, (B) log PLD versus log of the maximum study distance and (C) $\log$ PLD versus log $F_{\mathrm{ST}}$

Table 3. Correlations between pelagic larval duration (PLD) and genetic metrics for subsets of data with $\mathrm{n}>10$ from W\&T and the present study

\begin{tabular}{|c|c|c|c|c|c|c|}
\hline & \multicolumn{3}{|c|}{ All data } & \multicolumn{3}{|c|}{ PLD $>1$} \\
\hline & $\mathrm{R}^{2}$ & $\mathrm{p}$ & $\mathrm{n}$ & $\mathrm{R}^{2}$ & $\mathrm{p}$ & $\mathrm{n}$ \\
\hline \multicolumn{7}{|l|}{ Global $F_{\mathrm{ST}}$} \\
\hline \multicolumn{7}{|l|}{ All markers } \\
\hline $\mathrm{W} \& \mathrm{~T}$ & $0.29^{\mathrm{a}}$ & $<0.0001$ & 139 & $0.20^{\mathrm{a}}$ & $<0.0001$ & 117 \\
\hline IBD & $0.36^{\mathrm{a}}$ & $<0.0001$ & 55 & $0.27^{\mathrm{a}}$ & 0.0003 & 43 \\
\hline No IBD & $0.26^{\mathrm{a}}$ & 0.0036 & 30 & $0.28^{\mathrm{a}}$ & 0.0050 & 27 \\
\hline \multicolumn{7}{|l|}{ Microsatellites } \\
\hline $\mathrm{W} \& \mathrm{~T}$ & 0.34 & 0.0005 & 29 & 0.28 & 0.0085 & 24 \\
\hline IBD & 0.38 & 0.0008 & 26 & 0.16 & 0.0611 & 22 \\
\hline No IBD & 0.43 & 0.00064 & 16 & 0.48 & 0.0043 & 15 \\
\hline \multicolumn{7}{|l|}{ mtDNA } \\
\hline W\&T & 0.17 & 0.0119 & 36 & 0.14 & 0.0295 & 35 \\
\hline IBD & 0.47 & 0.0009 & 20 & 0.48 & 0.0120 & 12 \\
\hline \multicolumn{7}{|l|}{ Allozymes } \\
\hline W\&T & 0.25 & $<0.0001$ & 74 & 0.19 & 0.0006 & 58 \\
\hline \multicolumn{7}{|l|}{$F_{\mathrm{ST}} / \mathbf{k m}$} \\
\hline \multicolumn{7}{|l|}{ All markers } \\
\hline $\mathrm{W} \& \mathrm{~T}$ & $0.28^{\mathrm{a}}$ & $<0.0001$ & 139 & $0.16^{\mathrm{a}}$ & $<0.0001$ & 117 \\
\hline IBD & 0.61 & $<0.0001$ & 55 & 0.54 & $<0.0001$ & 43 \\
\hline No IBD & $0.35^{\mathrm{a}}$ & 0.0005 & 30 & $0.27^{a}$ & 0.0054 & 27 \\
\hline \multicolumn{7}{|l|}{ Microsatellites } \\
\hline W\&T & 0.36 & 0.0009 & 29 & 0.22 & 0.0194 & 24 \\
\hline IBD & 0.74 & $<0.0001$ & 26 & 0.56 & $<0.0001$ & 22 \\
\hline No IBD & 0.37 & 0.0121 & 16 & 0.47 & 0.0045 & 15 \\
\hline \multicolumn{7}{|l|}{ mtDNA } \\
\hline $\mathrm{W} \& \mathrm{~T}$ & 0.24 & 0.0024 & 36 & 0.25 & 0.0020 & 35 \\
\hline IBD & 0.42 & 0.0019 & 20 & 0.60 & 0.0031 & 12 \\
\hline \multicolumn{7}{|l|}{ Allozymes } \\
\hline $\mathrm{W} \& \mathrm{~T}$ & 0.25 & $<0.0001$ & 74 & 0.10 & 0.0135 & 58 \\
\hline \multicolumn{7}{|l|}{ IBD slope } \\
\hline \multicolumn{7}{|l|}{ IBD dataset } \\
\hline All & 0.34 & $<0.0001$ & 44 & 0.28 & 0.0008 & 36 \\
\hline Microsatellites & 0.38 & 0.0018 & 23 & 0.21 & 0.0466 & 19 \\
\hline MtDNA & 0.24 & 0.0768 & 14 & 0.28 & 0.1180 & 10 \\
\hline
\end{tabular}

The significant effect of marker type occurs because mtDNA studies showed a slightly higher mean $F_{\mathrm{ST}}$ than the other marker types for both datasets (i.e. intercepts differ when individual slopes are fit for the 3 subsets of marker types in the PLD vs. $F_{\mathrm{ST}}$ correlation; Fig. 5A,B). Because our interest is in the effect of PLD, not marker type, on $F_{\mathrm{ST}}$, we subtracted the mean $F_{\mathrm{ST}}$ value of each marker type for each data point to set all 3 intercepts to zero (without affecting slopes), thereby isolating the contribution of PLD (Fig. 5C,D). The fit of PLD vs. $F_{\mathrm{ST}}$ dropped about $30 \%$ for both datasets (IBD: $\mathrm{R}^{2}=0.36 ; \mathrm{W} \& \mathrm{~T}: \mathrm{R}^{2}=0.29$; Table 3). These 2 correlations are not significantly different (IBD: $\mathrm{r}=-0.623[-0.75,-0.44]_{\text {i }}$ W\&T: $r=-0.51[-0.61,-0.36])$. We also asked whether the PLD vs. $F_{\mathrm{ST}}$ fit varied across marker types and found all 3 showed similar fits; given the sample sizes, the correlation strengths are statistically indistinguishable (Table 3). For both datasets, microsatellite subsets had almost identical fits for PLD versus $F_{\mathrm{ST}}\left(\mathrm{R}^{2}=0.34\right.$ and 0.38$)$.

We asked whether the metric $F_{\mathrm{ST}} / \mathrm{km}$ would provide similarly improved fit with PLD for the W\&T dataset as it did for ours. After accounting for marker type as above, a GLM of $F_{\mathrm{ST}} / \mathrm{km}$ versus PLD showed no improved explanatory power over the use of $F_{\mathrm{ST}}$ for the W\&T dataset $\left(\mathrm{R}^{2}=0.28, \mathrm{p}<\right.$ 0.0001 , or $\mathrm{R}^{2}=0.16, \mathrm{p}<0.0001$ without direct developers; Table 3 ). It is not surprising that $F_{\mathrm{ST}} / \mathrm{km}$ performs poorly, because the W\&T studies were selected as a random subsampling of the published literature and were not limited to those that show a relationship between $F_{\mathrm{ST}}$ and distance as were the studies in the IBD dataset. 

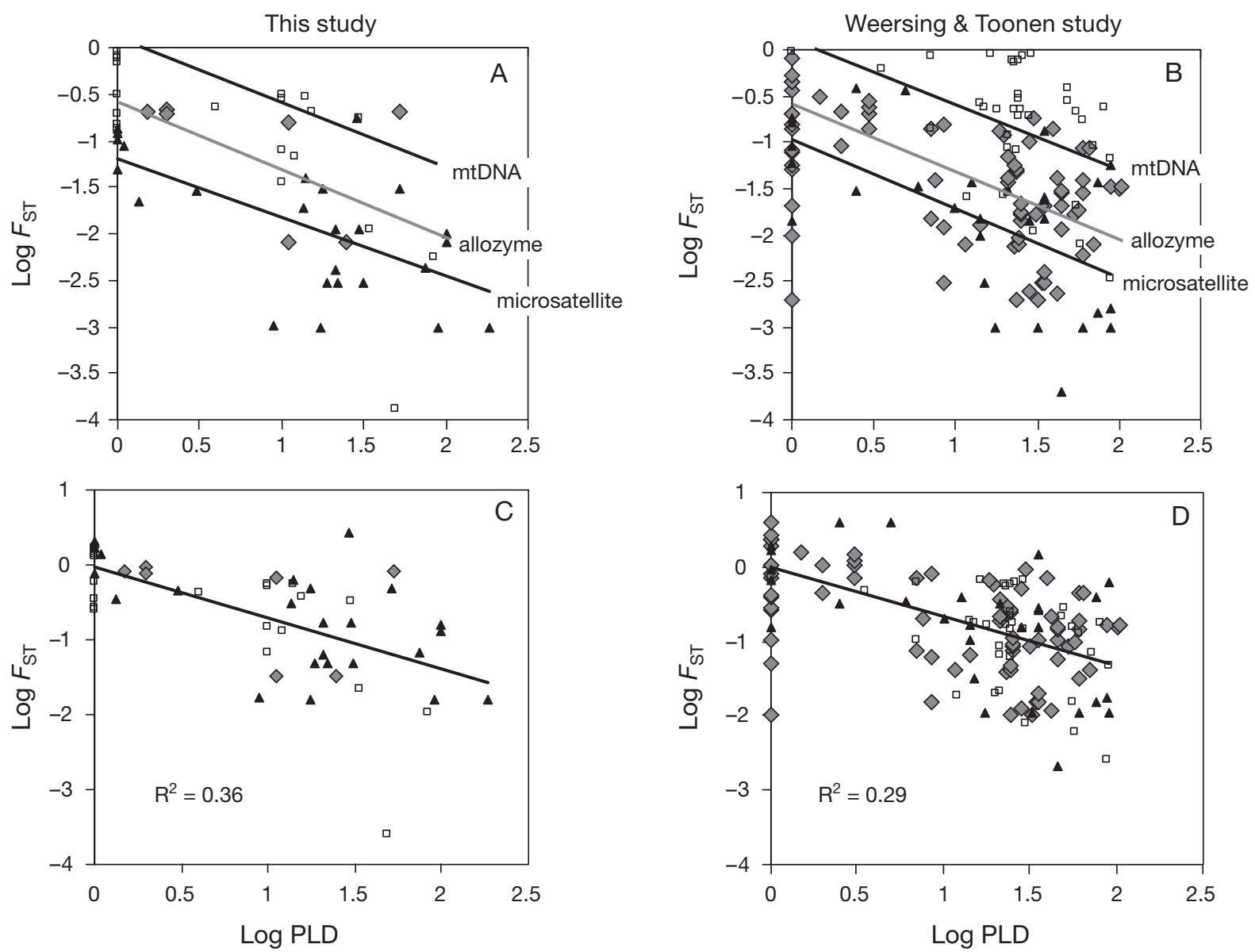

Fig. 5. The 3 marker types show distinct slopes for the correlation of pelagic larval duration (PLD) versus $F_{\text {STi }}$ open squares and upper black line used for mtDNA, grey diamonds and grey line for allozyme and black triangles and lower black line for microsatellite data. $F_{\mathrm{ST}}$ refers to global $F_{\mathrm{ST}}$. (A) Isolation-by-distance dataset from the present study and (B) from the W\&T dataset. Shifting all 3 intercepts to zero removes the effect of marker type on the correlation of PLD versus $F_{\mathrm{ST}}$ to isolate the fit of PLD and $F_{\mathrm{ST}}$. IBD dataset with all intercepts $=0,(\mathrm{C})$ from the present study and (D) from the W\&T dataset

\section{Comparison to studies with non-significant IBD}

The 'no IBD' dataset included studies that tested for IBD but failed to show IBD, indicating that $F_{\mathrm{ST}}$ does not increase linearly with distance, at least as measured. Thirty data points were included in the 'no IBD dataset' taken from 29 studies and representing 29 species: 7 fishes, 11 mollusks, 4 crustaceans, 3 echinoderms, 2 tunicates and 2 cnidarians (Table 2). Testing the same correlations of $F_{\mathrm{ST}}$ and $F_{\mathrm{ST}} / \mathrm{km}$ with PLD confirmed that this dataset behaved very similarly to the W\&T dataset (Table 3). All 3 datasets, W\&T, IBD and 'no IBD,' show a comparable and modest fit for the PLD versus $F_{\mathrm{ST}}$ relationship when accounting for marker type $\left(R^{2}=0.26\right.$ to 0.36 ; Table 3$)$, and when microsatellite studies were isolated $\left(\mathrm{R}^{2}=0.34\right.$ to 0.43 ; Table 3$)$. Also, as expected, study scale showed no correlation with PLD $\left(\mathrm{R}^{2}=0.01\right)$ for the 'no IBD' dataset, in contrast to the IBD dataset.

\section{Other factors affecting genetic estimates}

We examined other potential influences on genetic estimates used in the analyses above aside from PLD and marker type. There was a significant negative correlation of IBD slope with the number of individuals sampled per population $\left(R^{2}=0.22, p=0.0028, n=44\right)$, indicating that IBD slopes are inflated when populations are poorly sampled. Global $F_{\mathrm{ST}}$ also showed a negative relationship with individuals sampled for the pooled IBD and no IBD datasets $\left(R^{2}=0.16, p=0.0002\right.$, $\mathrm{n}=85$; results were also similar for each dataset independently), indicating either that estimates of genetic differentiation are inflated when populations are poorly sampled, or researchers tend to boost sample size when low or no differentiation is found. Although individuals sampled is somewhat confounded with marker type (mtDNA studies tend to use smaller samples), the effect remains significant after accounting for 
marker type. Microsatellite studies alone showed significance for these sampling trends (individuals sampled vs. IBD slope: $\mathrm{R}^{2}=0.27, \mathrm{p}=0.012$; individuals vs. $\left.F_{\mathrm{ST}}: \mathrm{R}^{2}=0.14, \mathrm{p}=0.017\right)$. MtDNA studies also showed a significant negative correlation for individuals sampled versus $F_{\mathrm{ST}}\left(\mathrm{R}^{2}=0.26, \mathrm{p}=0.004\right)$, but no relationship for individuals samples versus IBD slope $\left(\mathrm{R}^{2}=\right.$ $0.08, p=0.31$ ). Number of populations sampled had no significant effect on any of the genetic metrics used here, despite the common recommendation to sample more than 5 to 10 populations when testing IBD. However, number of populations did show a significant negative correlation with IBD goodness-of-fit, which affects the statistical power of slope significance testing $\left(\mathrm{R}^{2}=0.17, \mathrm{p}=0.004, \mathrm{n}=46\right)$.

Because theory suggests that estimates of genetic structure are best obtained at local scales (Rousset 2004), we tested whether smaller scale studies showed stronger correlations of IBD slope and $F_{\text {ST }}$ with PLD than larger scale studies. An obvious gap in the dataset between the 650 and $1000 \mathrm{~km}$ study scale provided a boundary between small- and large-scale categorizations. Indeed, the smaller scale studies (maximum pairwise distance $<650 \mathrm{~km}$, mean pairwise distance $=$ $338 \mathrm{~km}$ ) showed an improved correlation of IBD slope and PLD $\left(\mathrm{R}^{2}=0.50, \mathrm{p}=0.002, \mathrm{n}=17\right)$, whereas the larger scale ones (maximum pairwise distance $>1000 \mathrm{~km}$, mean pairwise distance $=3876 \mathrm{~km}$ ) showed no relationship $\left(\mathrm{R}^{2}=0.11, \mathrm{p}=0.10, \mathrm{n}=25\right.$; Fig. 6$)$. However, scale played no role for the PLD versus $F_{\mathrm{ST}}$ or PLD versus $F_{\mathrm{ST}} / \mathrm{km}$ relationships for small- and large-scale studies - slopes, intercepts and $\mathrm{R}^{2}$ values were similar for the small- and large-scale subsets - for both the W\&T and IBD datasets. The 'no IBD' dataset showed improved fits for both $F_{\mathrm{ST}}$ and $F_{\mathrm{ST}} / \mathrm{km}$ with PLD at smaller scales (smaller scale: $\mathrm{R}^{2} \sim 0.75, \mathrm{n}=7$; larger scale: $\mathrm{R}^{2} \sim 0.24, \mathrm{n}=24$ ), but sample sizes were low.

Recent studies have suggested that $F_{\mathrm{ST}}$ values should be standardized for varying diversity levels of markers or genomes before comparison (Hedrick 2005, Meirmans 2006, Jost 2008). Lack of standardization may create a source of noise or bias in our $F_{\mathrm{ST}}$ correlations. However, using mean within-population expected heterozygosity as a surrogate for total heterozygosity (which is not widely reported) in a calculation of Hedrick's corrected $F_{\mathrm{ST}}$ did not lead to any improvement in fit for either PLD versus $F_{\mathrm{ST}}$ or PLD versus $F_{\mathrm{ST}} / \mathrm{km}$ for the IBD dataset.

No evidence of taxonomic influence was apparent in the data. Fishes and mollusks were the best represented marine taxa in both the IBD and no IBD datasets (Table 2). Neither dataset showed differing trends in PLD versus $F_{\mathrm{ST}}, F_{\mathrm{ST}} / \mathrm{km}$, or IBD slope for these 2 taxa, despite having significantly different mean PLDs (fishes: 60 d, mollusks: 19 d; direct developers excluded).

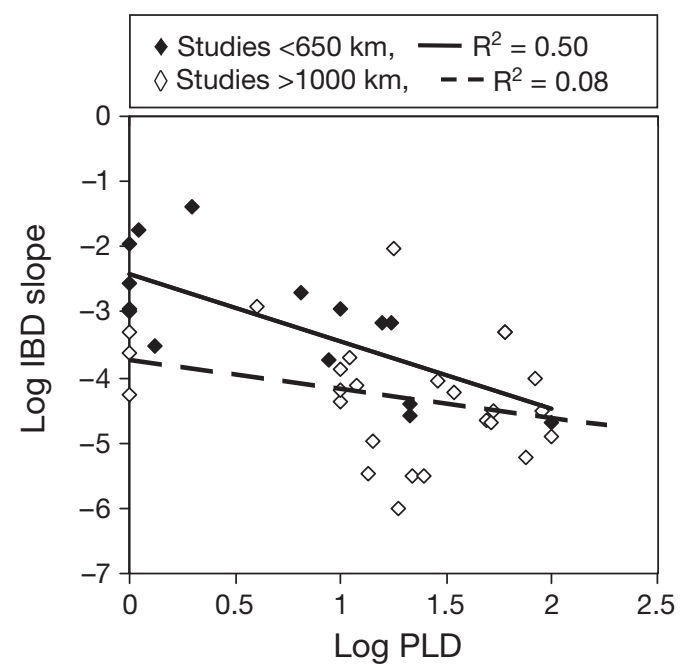

Fig. 6. Pelagic larval duration (PLD) versus isolation-bydistance (IBD) slope for the IBD dataset with studies $<650 \mathrm{~km}$ maximum pairwise distance $(\diamond)$ and studies with $>1000 \mathrm{~km}$ maximum pairwise distance $(\diamond)$ regressed separately. Two studies, with intermediate maximum pairwise distances of 800 and $900 \mathrm{~km}$ are not shown, but do not change the basic results no matter which category they are lumped into

\section{DISCUSSION}

Our dataset corroborates the significant positive relationship between PLD and IBD slope reported in Siegel et al. (2003), but casts doubt on the very high explanatory power they presented. Their dataset is actually based on 3 different metrics. The combination of metrics challenges interpretability of the results because the behavior of each differs, and this difference explains why there is no correlation between the IBD slopes they used and the global $F_{\text {ST }}$ values reported in the sources. Using a larger, more recent set of studies all compared using the same metric, our finding of $\mathrm{R}^{2}=0.34$ for the PLD versus IBD relationship is less than half of what was presented in Siegel et al. (2003).

Our hypothesis that IBD slopes would correlate better with PLD than do global $F_{\mathrm{ST}}$ values was not supported. This was surprising for several reasons. Theory suggests a more direct relationship between dispersal distance and IBD slope compared to global $F_{\mathrm{ST}}$ because $F_{\text {ST }}$ relates to a migration rate and IBD slope relates to a dispersal distance (Palumbi 2003). Also, an understanding of coastal oceanography would suggest that the stepping stone model underlying the IBD relationship is more often a better representation of connectivity for marine species than the island model underlying global $F_{\mathrm{ST}}$ (Palumbi 2003). Furthermore, when IBD is found, it is a suggestion that at least some of the assumptions behind $F_{\mathrm{ST}}$-based estimates of population structure are appropriate, compared to studies that do 
not find IBD. Instead, the W\&T dataset, as well as our new IBD and no IBD datasets, all indicate that roughly a quarter to a third of variance in $F_{\mathrm{ST}}$ or IBD slope is explained by PLD, depending on whether direct developers are excluded or included. The substantial change in the outcome of the PLD versus $F_{\mathrm{ST}}$ relationship here from what is reported in W\&T is due to 2 changes in our re-analyses of those data: (1) the removal of $F_{\mathrm{ST}}=0$ outliers from the initial analyses because they are uninformative data and (2) the removal of the marker type signal from the PLD versus $\mathrm{F}_{\mathrm{ST}}$ relationship.

This level of correlation between genetic estimates and PLD can be considered substantial given that genetic and PLD metrics are not measuring the same thing and both have high measurement error. However, the correlation is far less than what was reported in Siegel et al. (2003), and it is important to acknowledge that our common proxies of dispersal scale come with high error or otherwise unaccounted for source noise. Similar to Shanks (2009) and W\&T, there were few species with $1<$ PLD $<10$ for which we could find genetic and PLD data, creating somewhat of a bimodal PLD distribution in the data.

Ascertaining why the fit of PLD versus $F_{\mathrm{ST}}$ is unaffected by the existence of IBD might best be explored using simulations to assess how both PLD and $F_{\text {ST }}$ are affected by breaking the assumptions of a stepping stone model in various ways. When IBD is not present, it indicates 1 or more of the following 4 possibilities: (1) populations are not in migration-drift equilibrium, so $F_{\mathrm{ST}}$ estimates may not be reliable; (2) population sizes vary across sites, making $F_{\mathrm{ST}}$ a poor proxy of migration rate; (3) currents or other factors controlling dispersal are complex enough to decouple dispersal distance from geographic distance, invalidating the stepping stone dispersal model and making PLD a poor proxy of dispersal distance; or (4) sampling was inadequate to detect IBD, which might also compromise $F_{\mathrm{ST}}$ estimates. Our results suggest that studies that fail to find IBD do not necessarily have less reliable $F_{\mathrm{ST}}$ estimates than studies that do show IBD (i.e. the correlation between global $F_{\mathrm{ST}}$ and PLD was very similar for the IBD and no IBD datasets; Table 3). This may suggest that Scenario 3 above, that currents are driving complexity in dispersal, is a common cause of lack of IBD. Our reasoning comes from the observation that Scenario 3 is the only one of the scenarios without clear collateral effects on interpreting global $F_{\mathrm{ST}}$ values as proxies of migration rate. However, simulations assessing how much $F_{\mathrm{ST}}$ and PLD actually misrepresent migration and dispersal under each of the 4 scenarios would be necessary to confirm this possible explanation for why global $F_{\mathrm{ST}}$ is no less reliable when IBD is not found.
It is important to note that our results do not contradict the fact that for any single study species, IBD slopes are still a more powerful way to investigate scales of connectivity than global $F_{\mathrm{ST}}$, given proper study design. Interestingly, the fit of PLD versus IBD improved considerably when studies with very large spatial scales were excluded. Theory advises that the IBD slope will be most accurate in estimating 'parent-offspring radius,' or dispersal scale, at the smallest scale at which it appears (Rousset 2004). Slopes are underestimated when distant site pairs are included in a linear fit because IBD saturates with distance (Fig. 2); this phenomenon has been confirmed for marine and anadromous species (Bradbury \& Bentzen 2007). Our hypothesis that IBD slopes should correlate better with PLD than global $F_{\mathrm{ST}}$ may have been supported if the quality of IBD studies had been better and/or the sample size of small-scaled IBD studies had been larger. Unfortunately, high-frequency sampling is still uncommon in the field, and we recommend that future empirical IBD studies make it a priority. Ideally, maximum study scale should be at least twice as large as the scale of dispersal (Rousset 2004), and sampling should be extensive enough to detect the breakpoint between the linear rise of IBD and the leveling off of differentiation at large distances, so that the linear fit can be limited to the nearest population pairs, as in Fig. 2. A spatially nested sampling design allows better resolution of the breakpoint of the linear IBD slope, and spatial replicates allow the variation in slope to be assessed. A recent analytical model of optimal sampling design for measuring gene flow also recommended clustering sampling around predicted or chosen source populations to detect better the shape of the decay in gene flow away from the source (Assuncao \& Jacobi 1996).

Puebla et al. (2009) represents a good study design for extracting dispersal-scale estimates from genetic IBD data. Their study also gathered detailed population density data so that uniformity of population size across space can be confirmed and so that IBD slopes could be transformed into dispersal rate and mean parent-offspring dispersal distances. In the case of the study species, a small Caribbean reef fish, mean dispersal distance estimated from the genetic analyses was $<15 \mathrm{~km}$, which is much less than what passive diffusion would predict for the species' $3 \mathrm{wk}$ PLD. As the authors point out, this small dispersal scale and the small scale at which IBD emerges for this species $(175 \mathrm{~km})$, contrasts with the very large scale at which most IBD studies of marine species with multi-week PLDs are designed. Another recent study pairing IBD slope data with density also found dispersal distance estimates were $<15 \mathrm{~km}$ for an anemonefish with a PLD of $9 \mathrm{~d}$ (Pinsky et al. 2010). 
Our dataset also showed that when the number of individuals sampled per population is low, IBD slope and global $F_{\mathrm{ST}}$ values are higher, suggesting that poor sampling is associated with genetic differentiation. Additional pitfalls of poor study design on detecting IBD were demonstrated by a recent simulation study (Audzijonyte \& Vrijenhoek 2010) and a recent literature review (Jenkins et al. 2010). Simulations revealed that typical sampling designs, in which there is a combination of gaps in spatial coverage and high gene flow and/or use of a single mitochondrial marker, have inadequate power to detect IBD (Audzijonyte \& Vrijenhoek 2010). A literature review reported that the typical IBD study samples just 11 populations, and simulations based on these data indicate that sampling 11 populations typically provides only a $50 \%$ probability of detecting a significant IBD signal (Jenkins et al. 2010). The need to include more populations in IBD analysis was also suggested by another review of empirical IBD studies (Peterson \& Denno 1998). Our data also confirmed that IBD goodness-of-fit, which affects statistical power, is correlated with the number of populations sampled. It is possible that many of the study systems included in the W\&T and the 'no IBD' datasets are capable of showing IBD, but were not properly sampled. If so, it would help to explain the similarity in the PLD versus $F_{\mathrm{ST}}$ relationship between these datasets and the IBD dataset, which purportedly occupy different regions of parameter space. As a whole, these findings about the influence of sampling strength combined with the similarities in relationship to PLD between the IBD and 'no IBD' datasets suggest that IBD could be more common in marine species than the literature would indicate.

Proper sampling design and clearer expectations for the roles of dispersal distance and PLD in the scale of genetic structure will help to advance understanding of marine genetic connectivity. Our study suggests that PLD and geographic distance on average account for roughly one-third of the variance in spatial genetic patterns in marine species. While perfect measurements of each parameter might boost this value somewhat, the roles of other drivers of connectivity, such as emigration rate, self-recruitment rate and population size, potentially account for similar levels of variance in genetic patterns and should be investigated as thoroughly as the role of interpopulation transport (Selkoe et al. 2010). Seascape genetics approaches, which extend the IBD framework to include other influences on population structure, are playing a central role in this process. In addition, finding statistical approaches that can move beyond a simplistic focus on a single mean dispersal distance for a given species in a given study region, and instead report on the variance or the entire distribution, a.k.a. 'dispersal kernel,' of dispersal rates among all locations will be key to significant progress in the field of marine connectivity and its applications to conservation and management of marine resources.

Acknowledgements. This project was supported with funding from the National Marine Sanctuaries MOA 2005-008/66832. Thanks to Sarah Lester and Brian Kinlan for helpful contributions to improving this manuscript, and to 3 anonymous reviewers. Thanks to Kimberly Weersing, Sarah Lester and Greg Conception for sharing datasets, and thanks to Cynthia Riginos and co-authors for sharing their unpublished manuscript. Thanks to the National Center for Ecological Analysis and Synthesis for ongoing support to K.A.S. This is Contribution Number 1463 from the Hawai'i Institute of Marine Biology and SOEST No. 8433.

\section{LITERATURE CITED}

Assuncao R, Jacobi CM (1996) Optimal sampling design for studies of gene flow from a point source using marker genes or marked individuals. Evolution 50:918-923

Audzijonyte A, Vrijenhoek RC (2010) When gaps really are gaps: statistical phylogeography of hydrothermal vent invertebrates. Evolution 64:2369-2384

Ayre DJ, Hughes TP (2000) Genotypic diversity and gene flow in brooding and spawning corals along the Great Barrier Reef, Australia. Evolution 54:1590-1605

Benjamini Y, Hochberg Y (1995) Controlling the false discovery rate: a practical and powerful approach to multiple testing. J R Stat Soc, B 57:289-300

Bohonak AJ (1999) Dispersal, gene flow, and population structure. Q Rev Biol 74:21-45

Bohonak AJ, Roderick GJ (2001) Dispersal of invertebrates among temporary ponds: Are genetic estimates accurate? Isr J Zool 47:367-386

Bradbury IR, Bentzen P (2007) Non-linear genetic isolation by distance: implications for dispersal estimation in anadromous and marine fish populations. Mar Ecol Prog Ser 340:245-257

Bradbury IR, Laurel B, Snelgrove PVR, Bentzen P, Campana SE (2008) Global patterns in marine dispersal estimates: the influence of geography, taxonomic category and life history. Proc R Soc Lond B 275:1803-1809

> Broquet T, Petit EJ (2009) Molecular estimation of dispersal for ecology and population genetics. Annu Rev Ecol Evol Syst 40:193-216

Castric V, Bernatchez L (2003) The rise and fall of isolation by distance in the anadromous brook charr (Salvelinus fontinalis Mitchill). Genetics 163:983-996

Frankham R (1995) Effective population size/adult population size ratios in wildlife - a review. Genet Res 66:95-107

Goldson AJ, Hughes RN, Gliddon CJ (2001) Population genetic consequences of larval dispersal mode and hydrography: a case study with bryozoans. Mar Biol 138: 1037-1042

Gomez-Uchida D, Banks MA (2005) Microsatellite analyses of spatial genetic structure in darkblotched rockfish (Sebastes crameri): Is pooling samples safe? Can J Fish Aquat Sci 62:1874-1886

Hare MP, Nunney L, Schwartz MK, Ruzzante ED and others (2011) Understanding and estimating effective population size for practical application in marine species management. Conserv Biol 25:448-449 
Hedrick PW (2005) A standardized genetic differentiation measure. Evolution 59:1633-1638

Hellberg ME (1994) Relationships between inferred levels of gene flow and geographic distance in a philopatric coral, Balanophyllia elegans. Evolution 48:1829-1854

Hutchison DW, Templeton AR (1999) Correlation of pairwise genetic and geographic distance measures: inferring the relative influences of gene flow and drift on the distribution of genetic variability. Evolution 53:1898-1914

Jenkins DG, Carey M, Czerniewska J, Fletcher J and others (2010) A meta-analysis of isolation by distance: relic or reference standard for landscape genetics? Ecography 33:315-320

> Jost L (2008) G(ST) and its relatives do not measure differentiation. Mol Ecol 17:4015-4026

Kelly RP, Palumbi SR (2010) Genetic structure among 50 species of the northeastern Pacific rocky intertidal community. PLoS ONE 5:e8594

Kimura M (1953) 'Stepping-stone' model of population. Annu Rep Natl Inst Genet 3:62-63

Kinlan BP, Gaines SD (2003) Propagule dispersal in marine and terrestrial environments: a community perspective. Ecology 84:2007-2020

Leis JM, Hay AC, Howarth GJ (2009) Ontogeny of in situ behaviours relevant to dispersal and population connectivity in larvae of coral-reef fishes. Mar Ecol Prog Ser 379: 163-179

Lester SE, Gaines SD, Kinlan BP (2007) Reproduction on the edge: large-scale patterns of individual performance in a marine invertebrate. Ecology 88:2229-2239

Levin LA (2006) Recent progress in understanding larval dispersal: new directions and digressions. Integr Comp Biol 46:282-297

Lowe WH, Allendorf FW (2010) What can genetics tell us about population connectivity? Mol Ecol 19:3038-3051

Marshall DJ, Monro K, Bode M, Keough MJ, Swearer S (2010) Phenotype-environment mismatches reduce connectivity in the sea. Ecol Lett 13:128-140

> Meirmans PG (2006) Using the AMOVA framework to estimate a standardized genetic differentiation measure. Evolution 60:2399-2402

Mitarai S, Siegel DA, Watson JR, Dong C, McWilliams JC (2009) Quantifying connectivity in the coastal ocean with application to the Southern California Bight. J Geophys Res 114:C10026

> Morgan SG, Fisher JL (2010) Larval behavior regulates nearshore retention and offshore migration in an upwelling shadow and along the open coast. Mar Ecol Prog Ser 404:109-126

O'Connor MI, Bruno JF, Gaines SD, Halpern BS, Lester SE, Kinlan BP, Weiss JM (2007) Temperature control of larval dispersal and the implications for marine ecology, evolution, and conservation. Proc Natl Acad Sci USA 104: 1266-1271

Palumbi SR (2003) Population genetics, demographic connectivity, and the design of marine reserves. Ecol Appl 13: 146-158

Paris CB, Cherubin LM, Cowen RK (2007) Surfing, spinning, or diving from reef to reef: effects on population connectivity. Mar Ecol Prog Ser 347:285-300

Peterson MA, Denno RF (1998) The influence of dispersal and diet breadth on patterns of genetic isolation by distance in phyophagous insects. Am Nat 152:428-446

Pineda J, Porri F, Starczak V, Blythe J (2010) Causes of decoupling between larval supply and settlement and conse- quences for understanding recruitment and population connectivity. J Exp Mar Biol Ecol 392:9-21

Pinsky ML, Montes HR, Palumbi SR (2010) Using isolation by distance and effective density to estimate dispersal scales in anemonefish. Evolution 64:2688-2700

Pringle JM, Wares JP (2007) Going against the flow: maintenance of alongshore variation in allele frequency in a coastal ocean. Mar Ecol Prog Ser 335:69-84

> Puebla O, Bermingham E, Guichard F (2009) Estimating dispersal from genetic isolation by distance in a coral reef fish (Hypoplectrus puella). Ecology 90:3087-3098

Riginos C, Douglas KE, Jin Y, Shanahan DF, Treml EA (2011) Effects of geography and life history traits on genetic differentiation in benthic marine fishes. Ecography 34: $566-575$

Ross PM, Hogg ID, Pilditch CA, Lundquist CJ (2009) Phylogeography of New Zealand's coastal benthos. NZ J Mar Freshw Res 43:1009-1027

Rousset F (1997) Genetic differentiation and estimation of gene flow from $F$-statistics under isolation by distance. Genetics 145:1219-1228

Rousset F (2004) Genetic structure and selection in subdivided populations, Vol 40. Princeton University Press, Princeton, NJ

Selkoe KA, Watson JR, White C, Ben Horin T and others (2010) Taking the chaos out of genetic patchiness: seascape genetics reveals ecological and oceanographic drivers of genetic patterns in three temperate reef species. Mol Ecol 19:3707-3726

Shanks AL (2009) Pelagic larval duration and dispersal distance revisited. Biol Bull 216:373-385

Shanks AL, Grantham BA, Carr MH (2003) Propagule dispersal distance and the size and spacing of marine reserves. Ecol Appl 13:159-169

Shanks AL, Morgan SG, MacMahan J, Reniers A (2010) Surf zone physical and morphological regime as determinants of temporal and spatial variation in larval recruitment. J Exp Mar Biol Ecol 392:140-150

Siegel DA, Kinlan BP, Gaylord B, Gaines SD (2003) Lagrangian descriptions of marine larval dispersion. Mar Ecol Prog Ser 260:83-96

Siegel DA, Mitarai S, Costello CJ, Gaines SD, Kendall BE, Warner RR (2008) The stochastic nature of larval connectivity among nearshore marine populations. Proc Natl Acad Sci USA 105:8974-8979

Slatkin M (1993) Isolation by distance in equilibrium and nonequilibrium populations. Evolution 47:264-279

Toonen RJ, Pawlik JR (2001) Foundations of gregariousness: a dispersal polymorphism among the planktonic larvae of a marine invertebrate. Evolution 55:2439-2454

Weersing K, Toonen RJ (2009) Population genetics, larval dispersal, and connectivity in marine systems. Mar Ecol Prog Ser 393:1-12

Whitlock MC, McCauley DE (1999) Indirect measures of gene flow and migration: $F_{\mathrm{ST}}$ not equal $1 /(4 \mathrm{Nm}+1)$. Heredity 82:117-125

> Woodson CB, McManus MA (2007) Foraging behavior can influence dispersal of marine organisms. Limnol Oceanogr 52:2701-2709

Wright S (1931) Evolution in Mendelian populations. Genetics 16:97-159

> Wright S (1943) Isolation by distance. Genetics 28:114-138

Wright KJ, Higgs DM, Cato DH, Leis JM (2009) Auditory sensitivity in settlement-stage larvae of coral reef fishes. Coral Reefs 29:235-243

Submitted: February 16, 2011; Accepted: June 1, 2011

Proofs received from author(s): August 18, 2011 